J. CAMACHO-BUNQUIN*, M. FERRANDON, H. SOHN, D. YANG, C. LIU, P. A. I. DE LEON,

F. A. PERRAS, M. PRUSKI, P. C. STAIR*, M. DELFERRO* (ARGONNE NATIONAL LABORATORY, LEMONT, U.S. DEPARTMENT OF ENERGY AND IOWA STATE UNIVERSITY, AMES, AND NORTHWESTERN UNIVERSITY, EVANSTON, USA)

Chemoselective Hydrogenation with Supported Organoplatinum(IV) Catalyst on Zn(II)-Modified Silica

J. Am. Chem. Soc. 2018, 140, 3940-3951.

\section{Pt-Catalyzed Chemoselective Hydrogenation of Dienes and Nitroarenes}

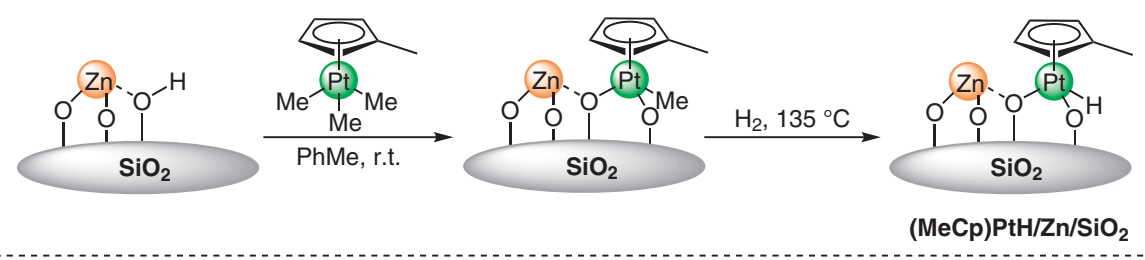

$86 \%$ conversion $89 \%$ mono-olefin selectivity
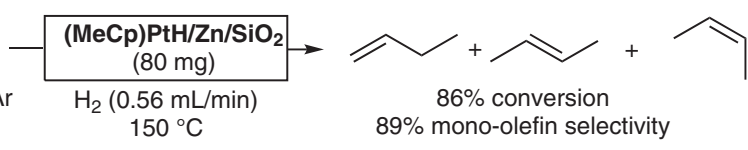

$$
\underset{\text { (MeCp)PtH/Zn/SiO }}{\stackrel{(0.04-0.08 \mathrm{~mol} \% \mathrm{Pt})}{\longrightarrow}}
$$<smiles>Nc1ccccc1OCCO</smiles>

9 examples

up to $>99 \%$ conversion up to $>99 \%$ selectivity

Results:

$$
\sim \mathrm{NH}_{2}
$$

$>99 \%$ conversion $>99 \%$ selectivity<smiles>Nc1ccc(C(=O)O[Na])cc1</smiles>

$>99 \%$ conversion
$>99 \%$ selectivity

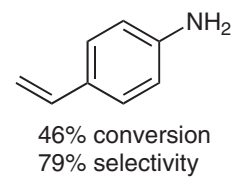

$79 \%$ selectivity

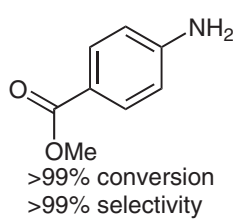

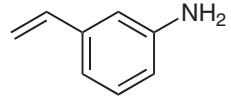

$55 \%$ conversion $84 \%$ selectivity

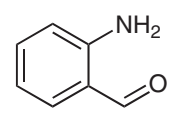

$>99 \%$ conversion $>99 \%$ selectivity
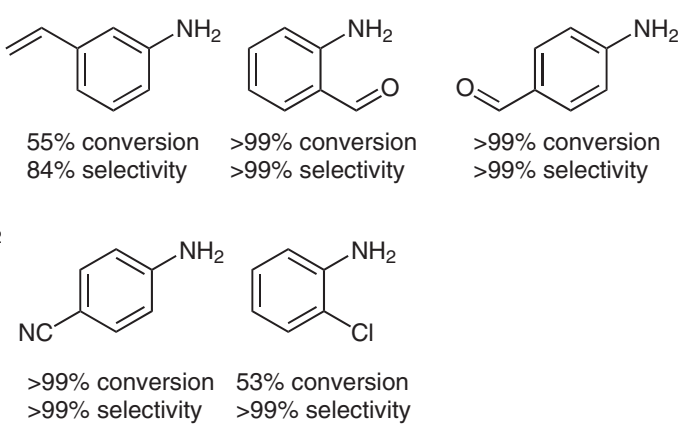

Gategory

Polymer-Supported Synthesis

\section{Key words}

hydrogenation

chemoselectivity

nitroarenes

platinum catalysis

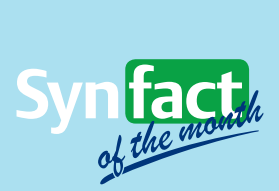

Significance: An organoplatinum(IV) catalyst supported on $\mathrm{Zn}(\mathrm{II})$-modified $\mathrm{SiO}_{2}$ [(MeCp)PtH/Zn/ $\mathrm{SiO}_{2}$ ], prepared as shown in equation 1, catalyzed the semihydrogenation of buta-1,3-diene under $\mathrm{H}_{2}$ to afford butenes in $86 \%$ conversion with $89 \%$ mono-olefin selectivity (eq. 2). The catalyst also promoted the chemoselective hydrogenation of nitrobenzenes bearing various reducible substituents, such as alkene, nitrile, or carbonyl groups, to afford the corresponding anilines in up to $>99 \%$ conversion and up to $>99 \%$ selectivity, with the substituents remaining intact (eq. 3).
Comment: The catalyst was characterized by means of solid-state NMR, XANES, EXAFS, PXRD, HR-TEM, TPR- $\mathrm{H}_{2}, \mathrm{NH}_{3}$-TPD, DRIFTS, DRUV-vis, and elemental analyses. In the hydrogenation of nitrobenzene, the catalyst was recovered by decantation and reused twice without loss of its catalytic activity.

SYNFACTS Contributors: Yasuhiro Uozumi, Aya Tazawa

Synfacts 2018, 14(06), 0649 Published online: 17.05.2018 Dol: 10.1055/s-0037-1609962; Reg-No.: Y05918SF 